\title{
Cyanine Tandem and Triple-Junction Solar Cells
}

Hui Zhang ${ }^{1}$, Bjoern Niesen ${ }^{2}$, Erwin Hack $^{3}$, Sandra Jenatsch ${ }^{1,5}$, Lei Wang ${ }^{1}$, Anna C. Véron ${ }^{1}$, Mohammed Makha ${ }^{1}$, René Schneider ${ }^{1}$, Yadira Arroyo ${ }^{4}$, Roland Hany ${ }^{1}$, Frank Nüesch ${ }^{1,5}{ }^{*}$

${ }^{1}$ Empa, Swiss Federal Institute for Materials Science and Technology, Laboratory for Functional Polymers, $\mathrm{CH}$ 8600 Dübendorf, Switzerland.

${ }^{2}$ Ecole Polytechnique Fédérale de Lausanne (EPFL), IMT, Photovoltaics and Thin Film Electronics Laboratory, Breguet 2, CH-2000 Neuchâtel, Switzerland.

${ }^{3}$ Empa, Swiss Federal Institute for Materials Science and Technology, Reliability Science and Technology, CH8600 Dübendorf, Switzerland.

${ }^{4}$ Empa, Swiss Federal Institute for Materials Science and Technology, Electron Microscopy Center, CH-8600 Dübendorf, Switzerland.

${ }^{5}$ Institut des Matériaux, Ecole Polytechnique Fédérale de Lausanne, EPFL, Station 12, CH-1015 Lausanne, Switzerland.

* Correspondence should be addressed to Prof. Dr. Frank Nüesch

Empa

Überlandstr. 129

CH-8600 Dübendorf

Switzerland

Phone: +4158 765 4740; fax: +41 58765 4012;

e-mail: frank.nueesch@empa.ch

Keywords organic photovoltaics, tandem cell, triple junction solar cell, cyanine dyes, intermediate layer 
Abstract

Ultrathin bilayer heterojunction solar cells using cyanine electron donors and electron acceptor $\mathrm{C}_{60}$ are used to fabricate monolithically stacked tandem and triple junction devices. Sub-cell stack sequences as well as $C_{60}$ layer thicknesses are optimized by optical modelling and maximum efficiency is corroborated experimentally. The highest power conversion efficiency of $4.3 \%$ under full sun irradiation is achieved with a tandem cell where heptamethine and trimethine cyanine dyes are used in the front and back cell, respectively. The open circuit voltage matches the sum of the two respective open circuit voltages of the individual single junction solar cells within $3 \%$. Triple junction cells using an additional sub-cell with a pentamethine cyanine suffer from electrical series resistance. At low light irradiation intensity, however, both triple and tandem solar cells reach power conversion efficiencies above $5 \%$ in agreement with the performance increase predicted from numerical simulation. 


\section{Introduction}

Cyanine dyes are well known as sensitizers in silver halide photography[1], as fluorescent biomarkers[2] or as light-absorbing layers in optical data storage devices[3]. These polymethine dyes have rarely been used as solid organic semiconductors but show high promise due to very high absorption coefficients, tuneable absorption spectrum and the ability to form aggregates with highly delocalized excitons[4]. Facile and cost effective synthesis of soluble cyanines with good film forming properties add to the merits of this materials class as active semiconductors in organic photovoltaic devices (OPV)[5]. The first use of cyanine dyes as solid organic semiconductor material dates back to 1965 when Meier et al. discovered photoconductivity in thin cyanine films[6]. Much later first attempts were undertaken to use trimethine carbocyanine dyes as donors and acceptors in planar bilayer heterojunction devices[7]. Even though maximum external quantum efficiencies of 75\% were achieved[8], best power conversion efficiencies (PCE) of 3.7\% in cyanine devices[9] still lag behind other small molecule semiconductors[10-12] and polymers[13-18] that recently reached PCE in excess of $8 \%$. The main reason for this shortcoming lies in the narrow absorption band of cyanine dyes, but also in the rather low charge carrier mobility which limits the active layer thickness to 20-30 $\mathrm{nm}$ [19]. While the narrow width of the absorption spectrum limits photocurrent in single junction devices, well defined complementary absorption spectra are beneficial in multi-junction devices.

Organic multi-junction solar cells have been realized as a stacked assembly of single junction devices being electrically connected either in series or in parallel[20]. First multijunction solar cells were simple mechanical stacks that hardly enabled to increase the power conversion efficiency in comparison with the constituting single junction solar cells[21, 22]. In some work, tandem cells were constructed out of single junctions employing the same materials which raised the efficiency due to an increased collection of photons and charge carriers[21, 23]. By now, design rules are well established to optimize efficiency in monolithically 
stacked multi-junction organic solar cells[21, 23-26]. Optical and electrical modelling are invaluable tools for hitting the maximum efficiency spot in the fabrication of these multilayer solar cells. When organic semiconductors with non-overlapping absorption spectra can be used, optical device optimization is particularly eased[27-29]. For example, it enables to position the low band-gap material to the front in order to optimize absorption[30]. To date, tan$\operatorname{dem}[10,31]$ and triple-junction[32] devices with PCE exceeding $10 \%$ and $11 \%$, respectively, have been reported. In both cases the multijunction solar cell outperformed the best constituting single junction cell by about $30 \%$. The big challenge for further improvements is to find organic semiconductors with complementary bandgaps in the near infrared domain as well as transparent and lossless recombination layers between the monolithically stacked cells. Furthermore, solution processed cells with low energy input are of particular economic and ecologic interest[33]. Owing to their wide range of bandgaps, high extinction coefficients, solution processability and easy accessibility, cyanine dyes are interesting candidates for organic multijunction solar cells.

In previous work, we demonstrated single junction solar cells based on trimethine dyes (Cy3-P) with a band gap of $\sim 1.8 \mathrm{eV}[34]$ as well as NIR absorbing heptamethine dyes[35] (Cy7-T) with a band gap of $1.2 \mathrm{eV}$ using a simple bilayer structure with $\mathrm{C}_{60}$ as electron acceptor. In this work we investigate tandem solar cells with Cy3-P and Cy7-T as well as triplejunction solar cells using the latter dyes and a complementary absorbing pentamethine cyanine dye (Cy5-P). We optimized the multilayer structures by varying the thickness of the $\mathrm{C}_{60}$ acceptor layers and changing the sub-cell sequence of the multijunction architecture using optical modelling based on transfer matrix formalism. Also, an efficient recombination layer composed of $\mathrm{MoO}_{3}$ and a very thin metal layer was optimized by varying the metal and its nominal thickness. The maximum efficiency reached for tandem solar cells at AM1.5G solar irradiation conditions was $4.3 \%$ which is approximately $34 \%$ higher than the efficiency of the best single junction cell employed in the stack. Triple-junction devices were optimized in the 
same way as tandem cells and reached $3.6 \%$ at full solar irradiation. Tandem and triplejunction devices both reached a PCE of $5.2 \%$ at one tenth of the full sun intensity.

\section{Experimental}

\subsection{Device fabrication}

All single, tandem and triple-junction solar cells were fabricated and stored in a glove box under nitrogen $\left(\mathrm{H}_{2} \mathrm{O}<1 \mathrm{ppm}, \mathrm{O}_{2}<10 \mathrm{ppm}\right)$. Indium tin oxide-coated glass substrates (ITO, Thin Film Devices, $140 \mathrm{~nm}$, sheet resistance $20 \mathrm{Ohm}$ /square) were sequentially cleaned in acetone, ethanol, detergent and de-ionized water. Layers of electron acceptor $\mathrm{C}_{60}$ (SES Research, $99.5 \%$ or $99.9 \%$ ), anode buffer $\mathrm{MoO}_{3}$ (Sigma Aldrich, 99.99\%), recombination metals Ag (Kurt J. Lesker, 99.99\%), Al (Kurt J. Lesker, 99.999\%) and Au (Kurt J. Lesker, 99.99\%) as well as cathode buffer tris(8-hydroxyquinolinato)aluminium ( $\mathrm{Alq}_{3}$, SigmaAldrich, 99.995\%) were deposited by thermal evaporation under high vacuum $\left(<5 \times 10^{-6}\right.$ mbar) at a rate of 0.1-0.3 A/s. Active electron donor films consisting of cyanine dyes 1-ethyl2-[3-(1-ethyl-3,3-dimethyl-1,3-dihydro-indol-2-ylidene)-propenyl]-3,3-dimethyl-3H-indolium hexafluorophosphate (Cy3-P, FEW Chemicals), 1,3,3-trimethyl-2-[5-(1,3,3-trimethyl-1,3dihydro-indol-2-ylidene)-penta-1,3-dienyl]-3H-indolium hexafluorophosphate (Cy5-P, FEW Chemicals) and heptamethine cyanine dye 2-[2-[2-chloro-3-[2-(1-ethyl-1,3-dihydro-3,3dimethyl-2H-indol-2-ylidene)ethylidene]-1-cyclohexen-1-yl]ethenyl]-1-ethyl-3,3-dimethyl3H-indolium trisphate (Cy7-T, synthesized in our group) were spin coated from filtered 2,2,3,3-tetrafluoropropanol (TFP, Sigma-Aldrich) or chlorobenzene (CB, Sigma-Aldrich) solutions (spin speed of $4000 \mathrm{rpm}$ for a typical duration of 1 minute). The reason for choosing the trisphat counteranion in Cy7-T comes from the superior performance of this donor in single junction solar cells as compared to the same heptamethine dye using $\mathrm{PF}_{6}{ }^{-}$as a counter an- 
ion[35]. The top silver electrode (Cerac, 99.99\%) was evaporated through a shadow mask to define devices with active areas of $3.1 \mathrm{~mm}^{2}$ or $7.1 \mathrm{~mm}^{2}$.

Bilayer single-junction devices with the general architecture ITO/ $\mathrm{MoO}_{3}(10 \mathrm{~nm}) /$ cyanine dye $(10 \mathrm{~nm}$ or $20 \mathrm{~nm}) / \mathrm{C}_{60}(40 \mathrm{~nm}) / \mathrm{Alq}_{3}(2 \mathrm{~nm}) / \mathrm{Ag}(100 \mathrm{~nm})$ were fabricated by subsequent deposition steps on cleaned ITO substrates. The cyanine donor layers were deposited from solution and left for $2 \mathrm{~h}$ under vacuum before depositing the $\mathrm{C}_{60}$ electron acceptor. TFP was used for Cy3-P and Cy5-P whereas CB was used in the case of Cy7-T. All other layers were deposited by thermal evaporation in the same vacuum chamber. Device fabrication starts with vapor deposition of $\mathrm{MoO}_{3}$ followed by solution deposition of the cyanine layer. For the spin coating step inside a glove box, devices need to be taken out of vacuum chamber and transferred back again for vapor deposition of the remaining layers. Since the vacuum chamber is directly connected to the glove box, samples are not contaminated by ambient atmosphere during the transfer.

Tandem devices were fabricated by using ten consecutive deposition steps to form two stacked junctions with general architecture ITO/ $\mathrm{MoO}_{3}(10 \mathrm{~nm}) / \mathrm{Cy} 7-\mathrm{T}(20 \mathrm{~nm}) / \mathrm{C}_{60}(x$ $\mathrm{nm}) / \mathrm{Alq}_{3}(2 \mathrm{~nm}) / \mathrm{RL}(z \mathrm{~nm}) / \mathrm{MoO}_{3}(10 \mathrm{~nm}) / \mathrm{Cy} 3-\mathrm{P}(10 \mathrm{~nm}) / \mathrm{C}_{60}(y \mathrm{~nm}) / \mathrm{Alq}_{3}(2 \mathrm{~nm}) / \mathrm{Ag}(100$ $\mathrm{nm}$ ) named Tan 7-3 in the following. The recombination layer (RL) consisted of evaporated Au with nominal thickness $z$ varying form $0.1 \mathrm{~nm}$ to $1 \mathrm{~nm}$. For comparison, $\mathrm{Ag}$ and $\mathrm{Al}$ were also used. In the best performing device structure (Tan 7-3), the $\mathrm{C}_{60}$ layer of the front cell had varying thicknesses $x$ ranging from $14 \mathrm{~nm}$ to $35 \mathrm{~nm}$, while the $\mathrm{C}_{60}$ thickness of the back cell was varied between $25 \mathrm{~nm}$ and $40 \mathrm{~nm}$. Similarly to single junction devices, substrates have to be taken out of the vacuum chamber for solution deposition of the cyanine layers. All other layers are deposited by thermal evaporation inside the same vacuum chamber.

Triple-junction solar cells consisted of fifteen deposited layers with the general structure $\mathrm{ITO} / \mathrm{MoO}_{3}(10 \mathrm{~nm}) / \mathrm{Cy} 7-\mathrm{T}(20 \mathrm{~nm}) / \mathrm{C}_{60}(x \mathrm{~nm}) / \mathrm{Alq}_{3}(2 \mathrm{~nm}) / \mathrm{Au}(0.5 \mathrm{~nm}) / \mathrm{MoO}_{3}(10 \mathrm{~nm}) / \mathrm{Cy} 3-$ 
$\mathrm{P}$ or Cy5-P $(10 \mathrm{~nm}) / \mathrm{C}_{60}(y \mathrm{~nm}) / \mathrm{Alq}_{3}(2 \mathrm{~nm}) / \mathrm{Au}(0.5 \mathrm{~nm}) / \mathrm{MoO}_{3}(10 \mathrm{~nm}) / \mathrm{Cy} 5-\mathrm{P}$ or Cy3-P $(10$ $\mathrm{nm}) / \mathrm{C}_{60}(20 \mathrm{~nm}) / \mathrm{Alq}_{3}(2 \mathrm{~nm}) / \mathrm{Ag}(100 \mathrm{~nm})$. Two promising sequences, both comprising Cy7$\mathrm{T}$ as front cell were investigated. The first (Tri 7-3-5) embeds Cy3-P in the middle cell and Cy5-P in the back cell, while the second (Tri 7-5-3) incorporates Cy5-P in the middle cell and Cy3-P in the back cell. As for single and tandem devices, only the cyanine films were deposited from solution, the other layers being deposited by vapor deposition under vacuum.

\subsection{Methods}

For solar cell characterization, the substrates were sealed in a vacuum tight box with current feedthroughs and an optical window. Current-voltage characteristics of the solar cells were measured using a Keithley 2400 source/measure unit in the dark and under simulated AM1.5G solar irradiation of $100 \mathrm{~mW} \mathrm{~cm}^{-2}$ from a calibrated solar simulator (Spectra-Nova). For reduced irradiation conditions, the white light intensity $P_{\text {in }}$ was passed through neutral density filters (Andover Corporation Optical Filter). Open-circuit voltage $\left(V_{O C}\right)$ and shortcircuit current-density $\left(J_{S C}\right)$ were obtained directly from the current-voltage characteristics. Power conversion efficiencies $(P C E)$ were calculated as $P C E=F F \times V_{O C} \times J_{S C} \times P_{i n}{ }^{-1}$, where $F F=(J \times V)_{\max } \times V_{O C}{ }^{-1} \times J_{S C}{ }^{-1}$ and $(J \times V)_{\max }$ relates to the current-density and voltage measured at the maximum power point. A Cornerstone 130 monochromator (Oriel) was used together with a $300 \mathrm{~W}$ Xe lamp to measure the incident photon-to-current conversion efficiencies (IP-

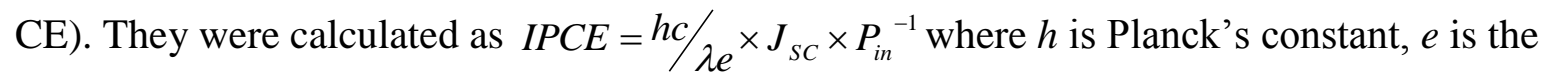
elementary charge and $\lambda$ is the monochromatic irradiation wavelength. The monochromatic light intensity was determined using a calibrated Si-diode. Reflection losses at the solar cell substrate were not considered in the calculation. It has been shown that solar cells based on cyanine layers can show pronounced effects on biasing[36, 37]. Such effects were not investigated in this work. 
The IPCE of multijunction solar cells was measured with a custom-built spectral response set-up equipped with lock-in amplifiers, a monochromator, and a Xenon lamp whose light was chopped at a frequency of $43 \mathrm{~Hz}$, without applying a bias voltage. The individual sub cells were measured utilizing appropriate combinations of blue, red, and near-infrared bias light, to generate high photocurrents in the sub cells not being measured. For this purpose, a halogen lamp with optical filters and LEDs were used. Specifically, for tandem cells, the Cy3-P IPCE was measured using a long pass filter with a cut-off wavelength of $630 \mathrm{~nm}$ (Schott RG-630) and the Cy7-T sub cell IPCE was measured using a Schott BG-23 band pass filter and a blue LED (470 nm emission peak). For triple-junction cells, the Cy3-P sub cell IPCE was measured with a RG-630 long pass filter and a blue LED, the Cy5-P sub cell IPCE with a RG-830 long pass filter and a blue LED, and the Cy7-T sub cell IPCE with a BG-23 band pass filter and a red LED (emission peak at $650 \mathrm{~nm}$ ).

Absorption spectra were measured on a Varian Cary 50 UV-vis spectrophotometer. Film thicknesses were determined by profilometry (Ambios XP1) and for $\mathrm{MoO}_{3}$ layers also by interference microscopy (Leica DCM8).

Optical constants $n$ and $k$ and film thicknesses for Cy3-P, Cy5-P and Cy7-T were determined by spectroscopic ellipsometry (M-2000, J.A.Woolam Co.) and served as input for the optical modelling based on the software setfos ${ }^{\circledR}$ (www.fluxim.ch). Details of these measurements are given in the supplementary data. In the case of $\mathrm{MoO}_{3}$, layer thicknesses were inferred from both interference optical microscopy analysis and profilometry and were prescribed for the modelling of the ellipsometric data (see supplementary data). The modelling took into account the full device layer stack including the conducting ITO glass substrate.

\section{Results and discussion}

Cyanine dyes are characterized by a cationic chromophore with two end-standing nitrogens connected by a polymethine bridge. The absorption of these dyes in solution is char- 
acterized by a narrow absorption spectrum and a huge maximum extinction coefficient. For Cy3-P the latter reaches $164000 \mathrm{M}^{-1} \mathrm{~cm}^{-1}, 210000 \mathrm{M}^{-1} \mathrm{~cm}^{-1}$ for Cy5-P and up to $360000 \mathrm{M}^{-}$ ${ }^{1} \mathrm{~cm}^{-1}$ for Cy7-T in CB. When coated as a thin solid film, the absorption maximum is red shifted and significantly broadened due to intermolecular interaction of the conjugated $\pi$-systems, which is particularly important for dyes with strong transition dipole moments. The molecular structures and thin film absorption spectra of the cyanines Cy3-P, Cy5-P and Cy7-T as well as fullerene $\mathrm{C}_{60}$ are shown in Fig. 1. By combining the tri-, penta- and heptamethine dyes, solar light in the range between $450 \mathrm{~nm}$ and $900 \mathrm{~nm}$ can be harvested. As deduced from the intersection of the absorption onset with the axis of abscissae, band gap energies of $1.8 \mathrm{eV}$ (Cy3P), $1.4 \mathrm{eV}(\mathrm{Cy} 5-\mathrm{P})$ and $1.2 \mathrm{eV}(\mathrm{Cy} 7-\mathrm{T})$ are obtained. It appears that the bandgaps of $1.8 \mathrm{eV}$ and $1.2 \mathrm{eV}$ would be quite ideal for inorganic semiconductor tandem cells, but that a lower bandgap would be needed for ideal triple layer devices. However, given the fact that the bandwidth of organic conjugated materials is much smaller than for inorganic semiconductors, organic multi-junction solar cells require case-by-case optimization.

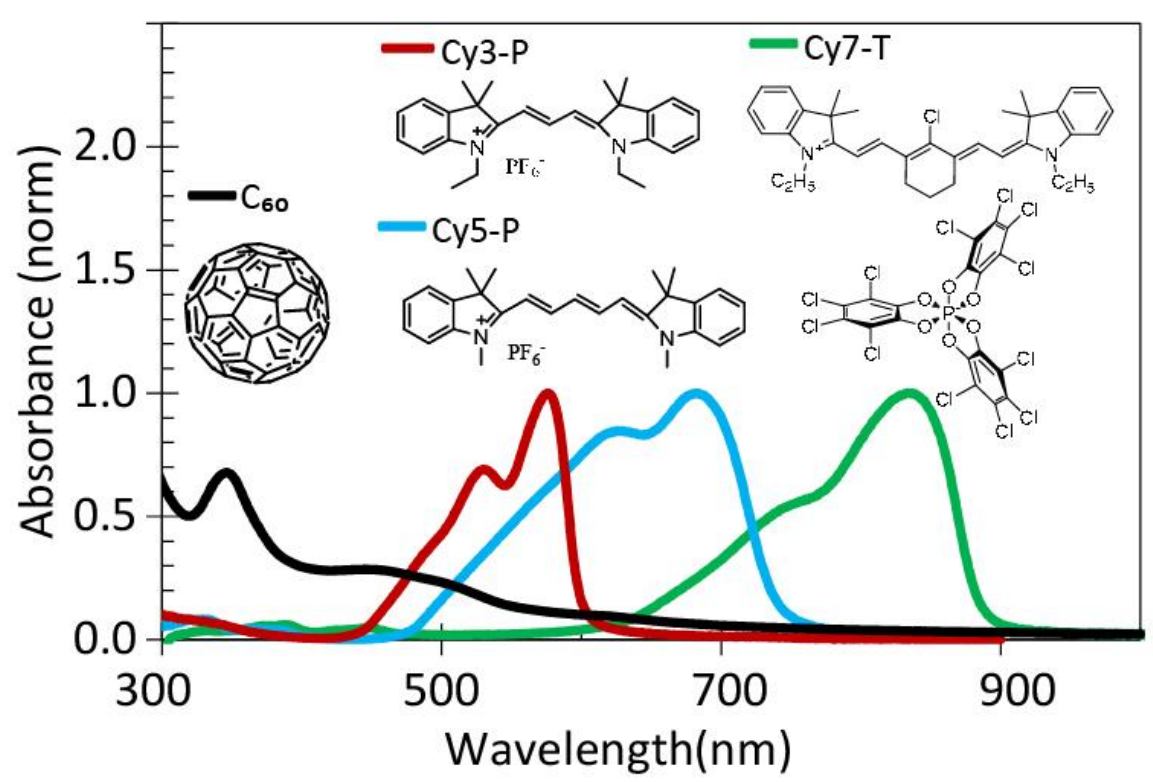

Fig. 1 Absorption spectra and molecular structures of $\mathrm{C}_{60}, \mathrm{Cy} 3-\mathrm{P}, \mathrm{Cy} 5-\mathrm{P}$ and Cy7-T. 
The performances of single junction solar cells composed of the different materials as well as the characteristic energy levels of the highest occupied molecular orbital (HOMO) and lowest unoccupied molecular orbital (LUMO) are given in Table 1 (J-V characteristics are given in Fig. S1). In order to balance light absorption, exciton diffusion and charge carrier transport, we kept the thin cyanine film absorbance at an optical density of 0.2 corresponding to layer thicknesses of $10 \mathrm{~nm}$ for Cy3-P and Cy5-P and $20 \mathrm{~nm}$ for Cy7-T as determined from ellipsometry measurements. Despite the small cyanine layer thickness used for all three devices, PCE of about 3\% could be obtained for all three cyanine solar cells. More important for constructing multi-junction devices is the fact that the short circuit current-density is matched between the cells, which is not the case for the optimized single layer devices in Table 1. For comparing modelled current densities with experimentally determined ones, light absorption was simulated using setfos ${ }^{\circledR}$ software. The optical model implemented in the setfos ${ }^{\circledR}$ absorption module is based on a modified transfer matrix formalism that allows calculating the photon flux across any optical stack. Input regarding layer thicknesses as well as the optical constants $n$ and $k$ as a function of wavelength (see supplementary data Fig. S2-S5) are required to compute the optical electric field distribution through the multilayer device in a coherent way. Thicker layers such as the $1 \mathrm{~mm}$ thick glass substrate are treated in an incoherent way. If it is assumed that every absorbed photon in the electron donor and acceptor material generates one electron in the external electric circuit, the maximum short circuit current $J_{S C \text {, max }}$ can be computed. A series of single junction cells were fabricated to determine the average ratio of $J_{S C}$, exp $/ J_{S C, \max }($ Table 1$)$, where $J_{S C, \exp }$ is the experimentally determined short circuit current. According to a published procedure, these values were then used as input for the model to calculate the scaled current density $J_{S C \text {, cal }}$ of tandem cells[38]. As displayed in Table 1, the experimental values $J_{S C \text {,exp }}$ are about half the theoretical maximum and reflect losses due to deficient exciton diffusion, exciton dissociation or charge carrier collection. About 10\% loss incurs due to optical reflection at the window of the measurement chamber. Series resistance imposed by 
the low hole mobility in cyanine films accounts for part of these losses, but for the ultrathin cyanine layers used, the $F F$ of $50-60 \%$ is nevertheless appreciably high for organic solar cell devices. The precise origin of the major bottleneck in this class of semiconductors is not fully understood, but is believed to be partly due to charge trapping induced by structural disorder. Limitation of exciton diffusion accounts for another part of the loss and is governed by the very short luminescence lifetime in cyanine films of about $50 \mathrm{ps}$ [39].

Table 1 Experimental and calculated performances of single junction cyanine dye solar cells

\begin{tabular}{c|ccccccccc}
\hline Device & $\begin{array}{c}\text { LUMO } \\
\mathrm{eV}\end{array}$ & $\begin{array}{c}\mathrm{HOMO} \\
\mathrm{eV}\end{array}$ & $\begin{array}{c}\text { VOC } \\
\mathrm{N}\end{array}$ & $\begin{array}{c}J_{S C, \exp } \\
/ \mathrm{mAcm}^{-2}\end{array}$ & $\begin{array}{c}J_{S C, \max } \\
/ \mathrm{mAcm}^{-2}\end{array}$ & $\begin{array}{c}J_{s c, \text { xx }} / J_{s c, \max } \\
1 \%\end{array}$ & $\begin{array}{c}F F \\
1 \%\end{array}$ & $\begin{array}{c}\eta_{\text {best }} \\
/ \%\end{array}$ \\
\hline $\begin{array}{c}\text { single Cy7-T cells } \\
\text { (CB) }\end{array}$ & 4.2 & 5.4 & 0.63 & 7.1 & 15.0 & 0.47 & 52 & 2.3 & 2.8 \\
$\begin{array}{c}\text { single Cy5-P cells } \\
\text { (TFP) }\end{array}$ & 4.0 & 5.4 & 0.64 & 7.2 & 14.6 & 0.49 & 62 & 2.8 & 2.9 \\
$\begin{array}{c}\text { single Cy3-P cells } \\
\text { (TFP) }\end{array}$ & 3.9 & 5.7 & 0.90 & 6.2 & 10.1 & 0.61 & 55 & 3.0 & 3.2 \\
\hline
\end{tabular}

All single junction devices have the same architecture, i.e. ITO/ $\mathrm{MoO}_{3}(10 \mathrm{~nm}) /$ cyanine dye $(10 \mathrm{~nm}$ for Cy3-P and Cy5-P, $20 \mathrm{~nm}$ for Cy7-T)/C $60(40 \mathrm{~nm}) / \mathrm{Alq}_{3}(2 \mathrm{~nm}) / \mathrm{Ag}(100 \mathrm{~nm})$. The solvents used to deposit the cyanine films are also indicated (CB: chlorobenzene, TFP: tetrafluoropropanol)

An ideal tandem device configuration using inorganic semiconductors has the wide band gap subcell positioned to the front, followed by smaller bandgaps with the smallest bandgap cell at the very back of the multijunction stack. However, due to the specific absorption profiles and interference effects in thin layer organic solar cells, certain devices are performing better with reversed layer sequence[40, 41].

Given the large number of stacked layer possibilities in multijunction devices, it is tedious to optimize the performance experimentally by altering the cell configuration in the stack and by varying the active layer thicknesses. Therefore the first step was to simulate tandem and triple-junction solar cells based on the single junction devices described above. For this purpose we used the optical module in setfos ${ }^{\circledR}$ to calculate the maximum current density for each subcell in the multi-junction device with different layer sequences by assuming that each photon absorbed in the active layer yields an electron collected at the electrode or recombination layer. The current through the multiple junction device is then dominated by the limiting sub- 
cell, which defines the external short circuit current density $J_{S C, \text { max }}$. To estimate the maximum PCE of the multiple junction devices, the open circuit voltage $V_{O C}$ is assumed to be equal to the sum of the open circuit voltages of the constituting sub cells (data taken from Table 1) and $F F=65 \%$ was taken for the fill factor. Besides the different combinations of cell sequences, device optimization also includes variation of the $\mathrm{C}_{60}$ layer thickness from $6 \mathrm{~nm}$ to $40 \mathrm{~nm}$ for each sub-cell in the multilayer device. Due to the physical constraints of cyanine bilayer heterojunction devices explained above, all cyanine layer thicknesses were chosen such as to obtain an absorbance of 0.2 . Recombination layers consisting of an $\mathrm{Alq}_{3}(2 \mathrm{~nm}) / \mathrm{Au}(1$ $\mathrm{nm}) / \mathrm{MoO}_{3}(10 \mathrm{~nm})$ structure were taken for the simulations and the maximum current density value was scaled to $J_{S C \text {, cal }}$ to determine a more realistic device efficiency. Fig. 2 displays the optimization procedure to find the ideal $\mathrm{C}_{60}$ layer thickness in the subcells composed of a tandem device using Cy7-T and Cy3-P. Clearly, higher efficiencies are obtained when Cy7-T is used as the front cell (denoted as Tan 7-3) reaching a PCE up to 5\% while tandem cells with Cy3-P as the front cell reach only about $3 \%$. Closer inspection of the light intensity distribution through the multilayer stack for the different device types reveals that the maximum NIR light intensity at $850 \mathrm{~nm}$ is always located in the front cells due to the thin active layer thickness for both sub-cells (see supplementary data Fig. S5).

(a)

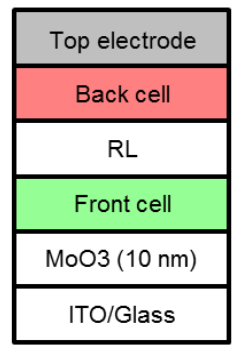

(b)

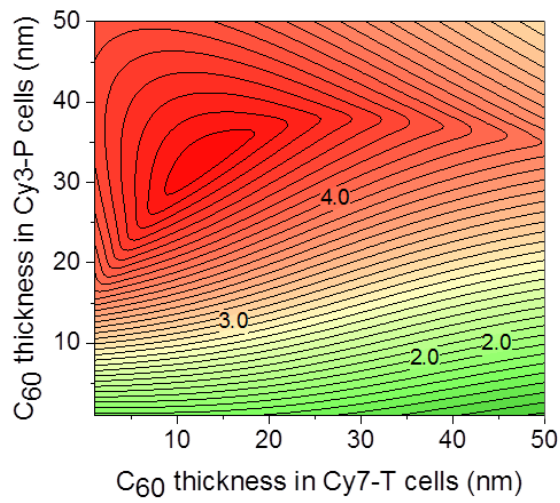

(c)

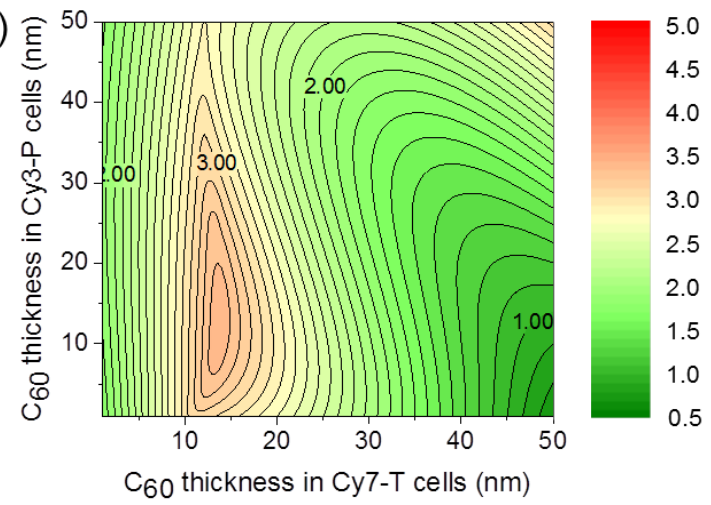

Fig. 2 Tandem device architecture (a) and simulated power conversion efficiency of tandem devices Tan 7-3 (b) and Tan 3-7 (c). The short circuit current density of the tandem solar cell 
was defined to be equal to the smaller of the short circuit currents of the individual sub-cells, respectively. Efficiency values were scaled using $J_{S C, \text { cal }}$ for the current density.

A similar nomenclature is used for triple junction devices. For example Tri 7-5-3 means that the cell incorporating Cy7-T is used as front cell, the one using Cy5-P constitutes the middle cell and Cy3-P the back cell, respectively. Fig. 3a displays the maximum current density $J_{S C}$, $\max _{\text {and efficiency }} \eta_{\max }$ of all tandem and triple-junction devices calculated by optimizing the $\mathrm{C}_{60}$ layer thicknesses as described above. The more realistic values for current density $J_{S C, c a l}$ and efficiency $\eta_{c a l}$ were then obtained using the factor $J_{S C, \text { exp }} / J_{S C \text {, max }}$ of the individual single junction cells (see Table 1) to scale the current density of each subcell (see Fig. 3b). Additionally, the single layer devices (e.g. Single Cy3) of Table 1 are also included. The latter provide the highest short circuit current densities but have lower efficiencies when compared to the multi junction devices. Clearly, Tan 7-3 outperforms all other tandem device configurations and was therefore chosen for experimental investigation. Regarding triple-junction solar cells, the highest efficiencies are above $8 \%$ for the maximum value $\eta_{\max }$ and about $5 \%$ for the scaled value $\eta_{\text {cal }}$. Tri 5-3-7 clearly shows the lowest performance among the different device architectures. Due to experimental difficulties of coating CB solutions of Cy7-T in Tri 3-7-5 or Tri 3-5-7 devices without re-dissolving the underlying $\mathrm{C}_{60}$ layer, only triple layer devices Tri 7-5-3 and Tri 7-3-5 were selected for further experimental investigations. 

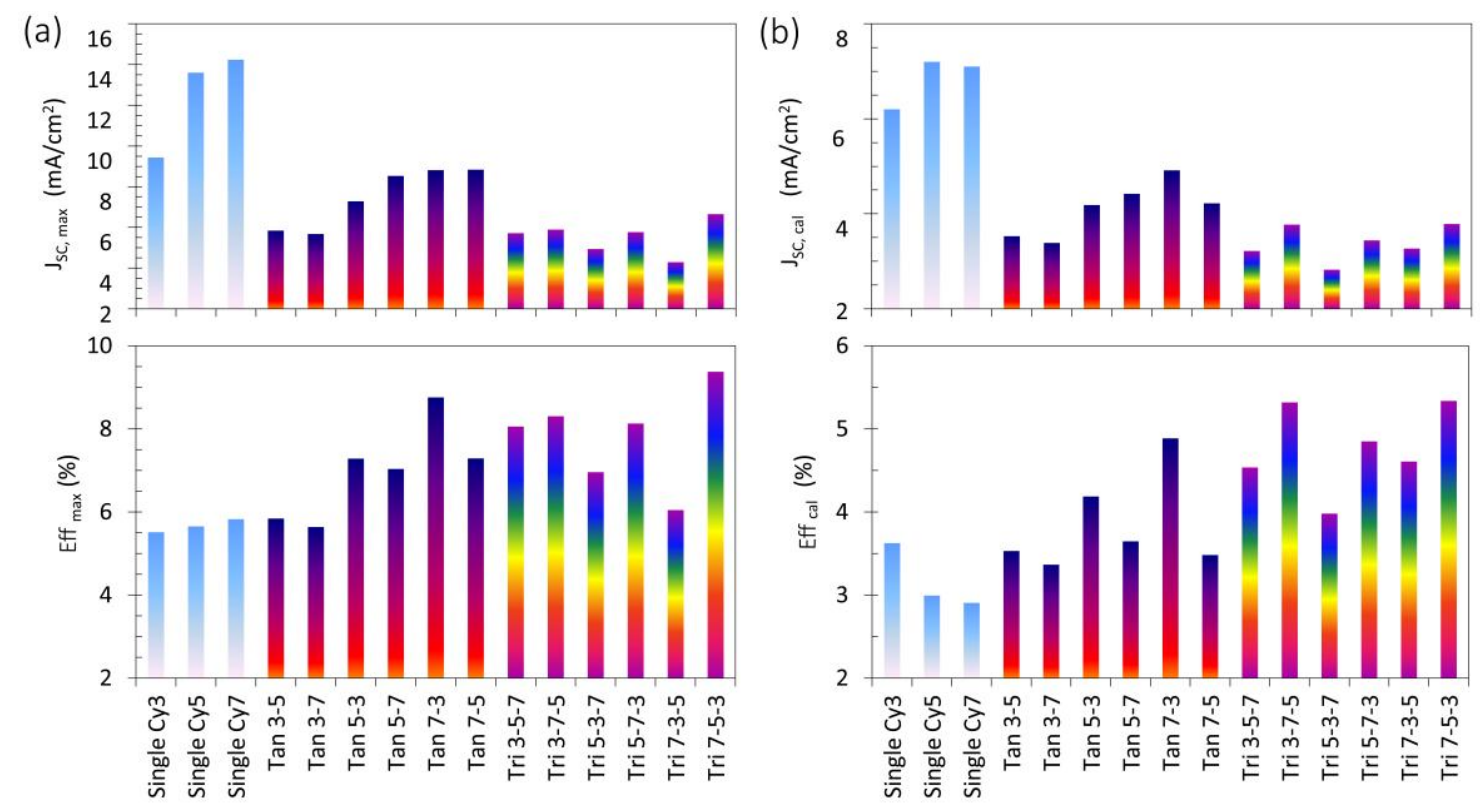

Fig. 3 a) Maximum current density $J_{S C \text {, } \max }$ and efficiency $\eta_{\max }$ of single junction (Single Cy3, Single Cy5, Single Cy7) and multi-junction devices with different layer sequences. The notation for tandem devices, e.g. Tan 3-5 indicates that the front cell uses cyanine dye Cy3-P while Cy5-P is used in the back cell. Triple junction solar cells follow a similar nomenclature, e.g. Tri 3-5-7 indicates that Cy3-P, Cy5-P and Cy7-T are used in front, middle and back cell, respectively. b) Scaled current density $J_{S C, c a l}$ and efficiency $\eta_{c a l}$ of single junction and multijunction cells.

The fabrication of monolithically stacked multjunction devices is analogous to single junction device fabrication, but bears additional difficulties. First, a recombination layer is necessary between two subsequent sub-cells in the stack. Negative charges from the front cell have to recombine with positive charges from the back cell through lossless contact, such that no voltage drop occurs across the interface. In classical inorganic tandem solar cells this is achieved by a tunneling contact between highly p- and n-doped layers. A similar approach has been adopted for organic solar cells deposited by vapor deposition[42]. Though, the difficulty is to avoid parasitic absorption and therefore the most widely used approach consists of using a combination of oxide films and ultrathin metallic layers[43-47]. The advantage of connecting the subcells in series is the fact that lateral conductivity is not required for the recombination layer. In order to increase optical transmission, the thin metallic layer therefore doesn't 
need to be continuous and can consist of fine clusters[48] or even metallic nanowires[49]. If solution processing is applied, the intermediate layer also serves as protecting layer in order to avoid diffusion of solvent into the underlying layers. Therefore the oxide layer in the stack has to be continuous and preferably dense. In this work we used a combination of ultrathin metal layers evaporated on $\mathrm{Alq}_{3}$ covered by a $10 \mathrm{~nm}$ thick $\mathrm{MoO}_{3}$ layer. The recombination between two solar cell junctions acts as cathode contact for one junction while it is an anode contact for the other junction. Numerous works confirmed that various metals such as $\mathrm{Au}, \mathrm{Ag}$ or $\mathrm{Al}$ do form Ohmic contacts to $\mathrm{C}_{60}$ when evaporated on a thin $\mathrm{Alq}_{3}$ layer[50-52]. On the other hand vapor deposited $\mathrm{MoO}_{3}$ thin films behave as excellent anode layers for cyanine single junction cells. To find the optimum recombination layer in the cyanine devices presented in this work, tandem solar cells with Tan 7-3 architecture were fabricated using different thin metal recombination layers. In absence of the highly conductive metal layer a strong S-shape and reverse diode characteristics under forward bias is observed (see Fig. 4a). 

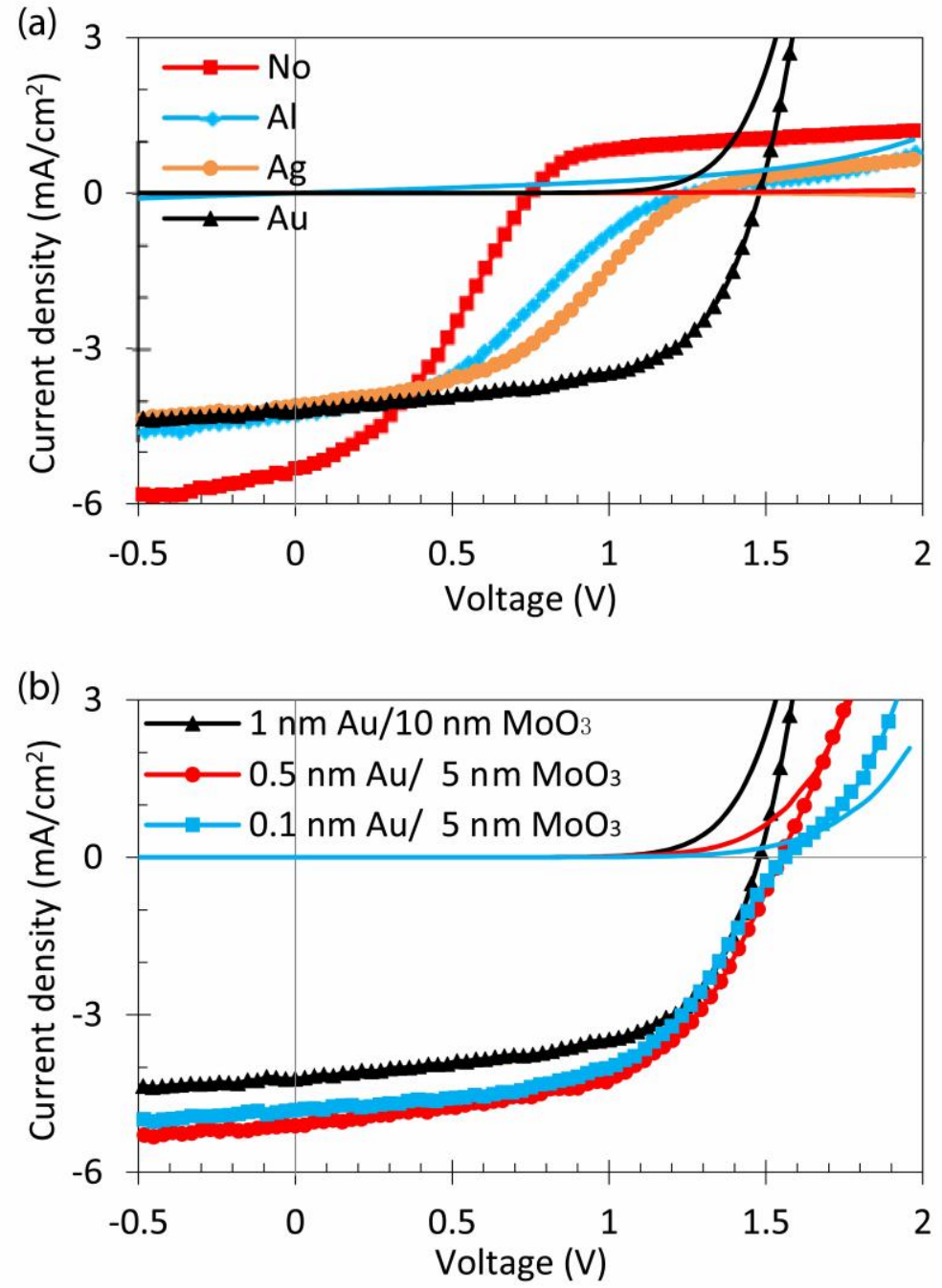

Fig. 4. (a) dark and light J-V curves of devices Tan 7-3 for different metals $\mathrm{Al}(1 \mathrm{~nm}), \mathrm{Ag}$ (1 $\mathrm{nm})$ and $\mathrm{Au}(1 \mathrm{~nm})$ as internal recombination center and combinations with $2 \mathrm{~nm} \mathrm{Alq} / \mathrm{met}-$ $\mathrm{al} / 10 \mathrm{~nm} \mathrm{MoO}_{3}$, (b) thickness variation of RL layer combinations using $\mathrm{Au}$, the other layer thicknesses were kept the same as for device 0 in Table 2.

Such behavior has already been observed in tandem devices missing a recombination layer[42, 53]. Reverse diode behavior can therefore originate from inverse junction formation between $\mathrm{Cy} 3-\mathrm{P}$ and $\mathrm{C}_{60}$ across the $\mathrm{MoO}_{3}$ layer. The growth of thin $\mathrm{MoO}_{3}$ layers on gold is known to proceed via a first, strongly interacting oxide monolayer that serves as wetting layer for the subsequent oxide layer[54]. Therefore the growth of the oxide intermediate layer depends also on the metal clusters being used as intermediate layers. Thin $1 \mathrm{~nm}$ films of $\mathrm{Al}$ or Ag did not provide the same quality of recombination layer and lead to non-ideal diode be- 
havior and reduced $V_{o c}$ in the tandem devices (Fig. 4a). AFM analysis of $10 \mathrm{~nm}$ thick $\mathrm{MoO}_{3}$ films deposited on $\mathrm{Au}, \mathrm{Ag}$ or $\mathrm{Al}$ films reveal the lowest film roughness on gold surfaces, thus supporting a more compact and continuous $\mathrm{MoO}_{3}$ film (see supplementary data Fig. S6).

$\mathrm{MoO}_{3}$ layers thinner than $5 \mathrm{~nm}$ always lead to low fill factors and S-shaped current-voltage characteristics. We attribute this behavior to the interdiffusion of $\mathrm{Cy} 3-\mathrm{P}$ when spin coating the back cell on top of $\mathrm{MoO}_{3}$. As revealed by scanning transmission electron microscopy analysis (STEM), evaporated $\mathrm{MoO}_{3}$ layers on glass indeed show a high degree of porosity (see supplementary data Fig. S7). The occurrence of voids in the $\mathrm{MoO}_{3}$ layer is also indicated by ellipsometric analysis where the best fit consists of a graded $\mathrm{MoO}_{3}$ layer model. In order to search for maximum cell performance, reflectivity and electrical resistance of the RL were minimized by further reducing the gold and $\mathrm{MoO}_{3}$ thickness to $0.1 \mathrm{~nm}$ and $5 \mathrm{~nm}$, respectively (see Fig. 4b). It has to be pointed out, however, that the device yield was lower than $30 \%$ in this case.

Table 2 Experimental and calculated performances for tandem devices Tan 7-3 with different $\mathrm{C}_{60}$ layer thickness

\begin{tabular}{c|cccccccc}
\hline Device & $\begin{array}{c}\left.C_{60}{ }^{a}\right) \\
(x, y) / \mathrm{nm}\end{array}$ & $\begin{array}{c}V_{O C} \\
\mathrm{~N}\end{array}$ & $\begin{array}{c}J_{S C, \text { exp }} \\
/ \mathrm{mAcm}^{-2}\end{array}$ & $\begin{array}{c}J_{S C, \text { cal }} \\
/ \mathrm{mAcm}^{-2}\end{array}$ & $\begin{array}{c}J_{S C, \text { exp }} / \\
J_{S C, \text { cal }}\end{array}$ & $\begin{array}{c}F F \\
/ \%\end{array}$ & $\begin{array}{c}\eta_{\text {average }} \\
/ \%\end{array}$ & $\begin{array}{c}\eta_{\text {best }} \\
/ \%\end{array}$ \\
\hline 0 & 14,32 & 1.46 & 4.52 & 4.83 & 0.94 & 59.6 & 3.93 & 3.98 \\
1 & 15,25 & 1.49 & 3.98 & 4.29 & 0.93 & 58.6 & 3.48 & 3.77 \\
2 & 15,30 & 1.49 & 4.01 & 4.66 & 0.86 & 57.5 & 3.45 & 3.51 \\
3 & 15,35 & 1.44 & 3.94 & 4.88 & 0.81 & 58.3 & 3.31 & 3.40 \\
4 & 15,40 & 1.43 & 3.82 & 4.67 & 0.82 & 59.2 & 3.23 & 3.61 \\
5 & 20,35 & 1.42 & 3.69 & 4.68 & 0.79 & 59.5 & 3.13 & 3.18 \\
6 & 25,35 & 1.44 & 3.78 & 4.53 & 0.83 & 59.2 & 3.22 & 3.56 \\
7 & 35,35 & 1.43 & 3.05 & 4.22 & 0.72 & 61.1 & 2.67 & 2.78 \\
$8^{\text {b) }}$ & 14,32 & 1.52 & 4.99 & 5.07 & 0.98 & 55.3 & 4.19 & 4.31 \\
$9^{\text {c) }}$ & 14,32 & 1.55 & 4.81 & 5.07 & 0.95 & 53.3 & 3.98 & 4.10 \\
\hline
\end{tabular}

a) $\mathrm{x}, \mathrm{y}$ refer to the $\mathrm{C}_{60}$ thicknesses in the front and back cells, respectively. For devices 0-7 the RL layer is: $2 \mathrm{~nm}$ $\mathrm{Alq}_{3} / 1 \mathrm{~nm} \mathrm{Au} / 10 \mathrm{~nm} \mathrm{MoO}$, b) RL layer is: $2 \mathrm{~nm} \mathrm{Alq} / 0.5 \mathrm{~nm} \mathrm{Au} / 5 \mathrm{~nm} \mathrm{MoO}$, averaged from 3 independent device batches (24 cells), c) RL layer is: $2 \mathrm{~nm} \mathrm{Alq} 3 / 0.1 \mathrm{~nm} \mathrm{Au} / 5 \mathrm{~nm} \mathrm{MoO}$. 
In order to optimize tandem devices experimentally and to verify the modelling results, multilayer solar cells with different $\mathrm{C}_{60}$ layer thicknesses were fabricated using a recombination layer incorporating a $1 \mathrm{~nm}$ thick Au layer and a $10 \mathrm{~nm}$ thick $\mathrm{MoO}_{3}$ film. For further optimization, thinner gold and $\mathrm{MoO}_{3}$ films were also used in specific cases (see Table 2). Given the short exciton diffusion length and limited hole transport mobility of cyanine films, layer thicknesses of cyanine donor films were chosen such as to provide a maximum absorbance of 0.2. As shown in Table 2 the variation of the $\mathrm{C}_{60}$ thicknesses in the front and back cell greatly influences the efficiency of the tandem devices. The open circuit voltage of $1.42 \mathrm{~V}$ to $1.55 \mathrm{~V}$ is only slightly affected and in the best case comes very close to the sum of VOC of the two single junction cells (the difference is only $2.6 \%$ ). On the other hand, the short circuit current density $J_{S C, \exp }$ varies considerably from $3 \mathrm{~mA} / \mathrm{cm}^{2}$ to $5 \mathrm{~mA} / \mathrm{cm}^{2}$. Given the good qualitative agreement with the modelled short circuit current $J_{S C, c a l}$, we conclude that the efficiency differences correlate with the light absorption profiles in the different multilayer stacks. The much higher theoretical current density maximum $J_{S C \text {, max }}$ indicates that important losses are reducing the power conversion efficiency besides incomplete light absorption. As explained before, losses could be due to exciton diffusion, exciton dissociation or charge transport. The latter point was assessed by operating the cell under reduced stimulated light intensity using neutral density filters (Fig. 5). The current density at one tenth of the solar irradiation intensity is about $0.67 \mathrm{~mA} / \mathrm{cm}^{2}$, which would correspond to $6.7 \mathrm{~mA} / \mathrm{cm}^{2}$ for a device with ideal linear response. Given the small decrease in $V_{O C}$ and the constant $F F$, this corresponds to a tandem efficiency of $5.2 \%$. Since $J_{S C \text { exp }}$ in single junction solar cells depends linearly on light intensity for photocurrents smaller than $5 \mathrm{~mA} / \mathrm{cm}^{2}$ (supplementary data Fig. S8), we attribute the current loss in tandem devices to the electrical resistivity of the recombination layer. As we will see below, the loss is even more pronounced for triple junction solar cells using two such junctions. 

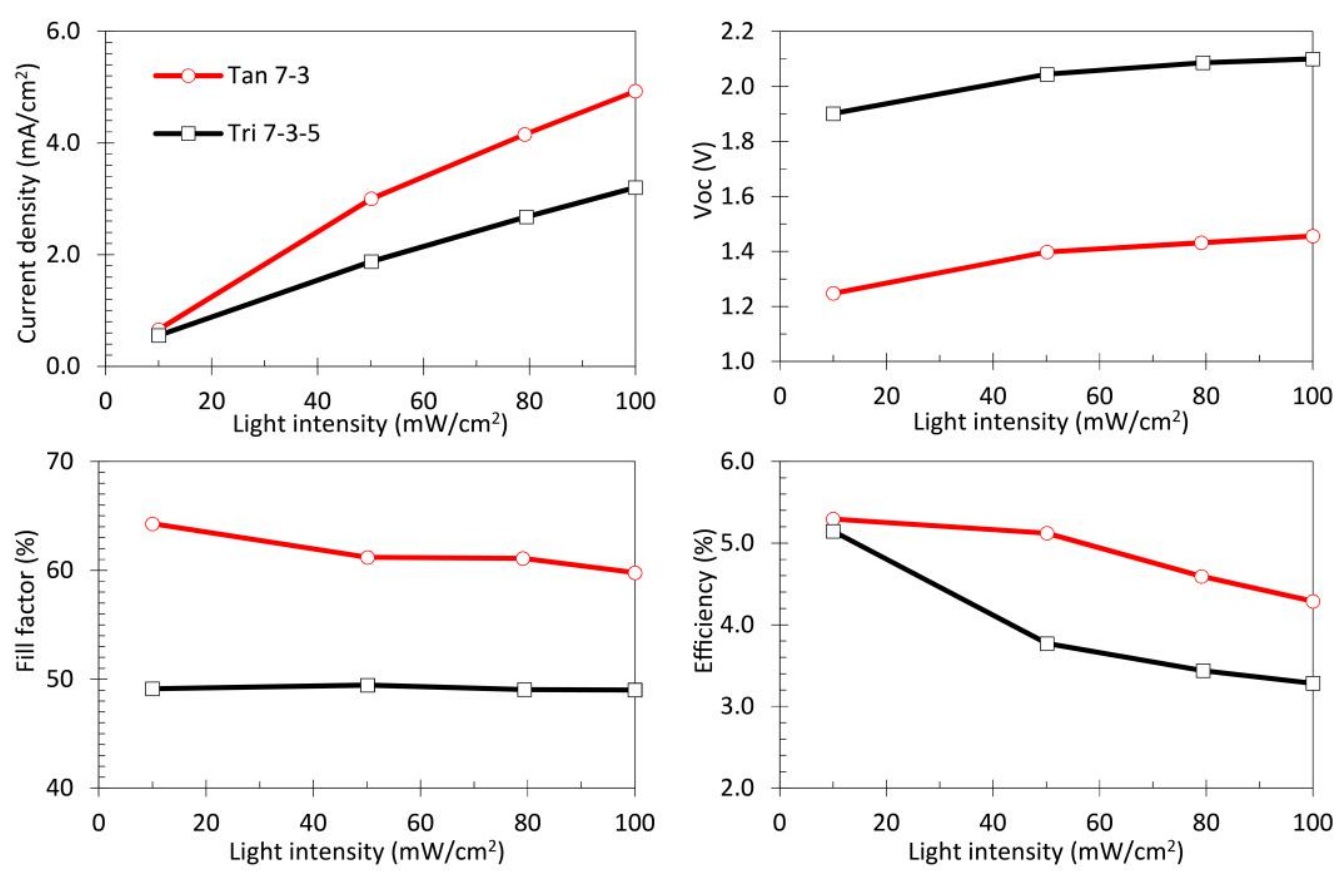

Fig. $5 J_{S C}, V_{O C}, F F$ and efficiency of the tandem cell and triple cell as functions of light intensity.

Triple junction devices were constructed with Cy7-T incorporated in the front cell. The reason for this choice is that Cy7-T is spin coated from chlorobenzene and would re-dissolve underlying $\mathrm{C}_{60}$ layers. Furthermore, cell configurations Tri 7-3-5 and Tri 7-5-3 showed high efficiencies in the modelling studies (Fig. 3). In analogy to tandem devices, we varied the $\mathrm{C}_{60}$ layer thicknesses of the individual junctions in the triple layer device stack (Table 3). This time, $V_{O C}$ varied quite substantially from $1.47 \mathrm{~V}$ to $2.11 \mathrm{~V}$. The reason is not so clear until now, but we identified that coating Cy3-P on a Cy5-P cell as the problematic step leading to inhomogeneous films. In the optimized Tri 7-3-5 cell $V_{O C}$ remarkably approaches the sum of the single junction cells (difference of $4.6 \%$ ). The short circuit current $J_{S C, \exp }$ showed less variation from $3.00 \mathrm{~mA} / \mathrm{cm}^{2}$ to $3.61 \mathrm{~mA} / \mathrm{cm}^{2}$. We note that the $J_{S C \text {,exp }}$ is considerably lower than the maximum calculated current density assuming an internal quantum yield of unity. This points towards current transport losses in the triple junction cell stack. The intensity dependence shown in Fig. 5 underlines the losses. At one tenth of the full sunlight intensity, a current density of $0.55 \mathrm{~mA} / \mathrm{cm}^{2}$ is measured, which would linearly extrapolate to $5.5 \mathrm{~mA} / \mathrm{cm}^{2}$ for ide- 
al behavior. As a matter of fact the efficiency of triple junction solar cells of $5.2 \%$ measured at 0.1 solar irradiation intensity comes very close to the one of tandem cells of $5.3 \%$ measured under the same conditions. Rather similar efficiencies $\eta_{c a l}$ have indeed been predicted by the modelling studies using scaled current densities for the individual subcells.

Table 3 Experimental and calculated performances for triple junction devices Tri 7-3-5 and Tri 7-5-3 with different $\mathrm{C}_{60}$ layer thicknesses (x,y,z refer to the $\mathrm{C}_{60}$ thicknesses in the bottom, middle and top sub-cell, respectively).

\begin{tabular}{ccccccc}
\hline Devices & $\begin{array}{c}C_{60} \text { thickness } \\
(x, y, z) / n m\end{array}$ & $\begin{array}{c}V_{O C} \\
N\end{array}$ & $\begin{array}{c}J_{S c, \text { exp }} \\
/ \text { mAcm }^{-2}\end{array}$ & $\begin{array}{c}F F \\
/ \%\end{array}$ & $\begin{array}{c}\eta_{\text {average }} \\
/ \%\end{array}$ & $\begin{array}{c}\eta_{\text {best }} \\
/ \%\end{array}$ \\
\hline Tri 7-5-3 & $10,12,20$ & 1.87 & 3.21 & 54.9 & 3.3 & 3.5 \\
Tri 7-5-3 & $8,10,20$ & 1.47 & 3.61 & 49.4 & 2.6 & 3.0 \\
Tri 7-5-3 & $10,10,20$ & 1.81 & 3.00 & 51.8 & 2.8 & 2.9 \\
Tri 7-3-5 & $8,10,20$ & 2.08 & 3.38 & 47.4 & 3.3 & 3.5 \\
Tri 7-3-5 & $10,12,20$ & 2.11 & 3.03 & 50.3 & 3.2 & 3.6 \\
Tri 7-3-5 & $10,10,20$ & 2.03 & 3.22 & 46.1 & 3.0 & 3.2 \\
\hline
\end{tabular}

In order to verify the short term stability of the multijunction solar cells, tandem and triple junction devices were aged in inert nitrogen atmosphere for more than one month in the absence of light. At room temperature, an initial degradation of the power conversion efficiency of $35 \%$ set in during the first 10 days (Fig. 6c). After this initial aging period the PCE stabilized and stayed constant for the next 40 days. When the same type of aging was carried out at the lowered temperature of $-15^{\circ} \mathrm{C}, \mathrm{PCE}$ did not noticeably change during the first 15 days of aging (Fig. 6c). Looking at the device characteristics (Fig. 6c) it appears that the $V_{O C}$ stayed unaffected by aging while the fill factor and to a lesser extent also $J_{S C}$ were most seriously reduced. The precise nature of this stabilization is not fully understood at the moment. However, since this phenomenon is not observed in single junction devices, there is strong evidence that deterioration of FF and $J_{S C}$ is related to the reconstruction of the RL. Gold atoms and clusters are able to diffuse into the organic layer during evaporation[55, 56]. They may also diffuse at the oxide interface[57-59], agglomerate or enter the pores of $\mathrm{MoO}_{3}$. As we have 
shown in Fig. 4, the effectiveness of the RL depends strongly on Au nanocluster formation. If the clusters are more widely spaced from each other when agglomerating at the interface, negative photogenerated charges may not be removed quickly enough by the RL and would therefore charge up the interface and lead to an S-shaped I-V curve. At low temperature, diffusion processes are slowed down which we also observe by the striking stabilization of PCE when reducing the storage temperature of devices (Fig. 6c).
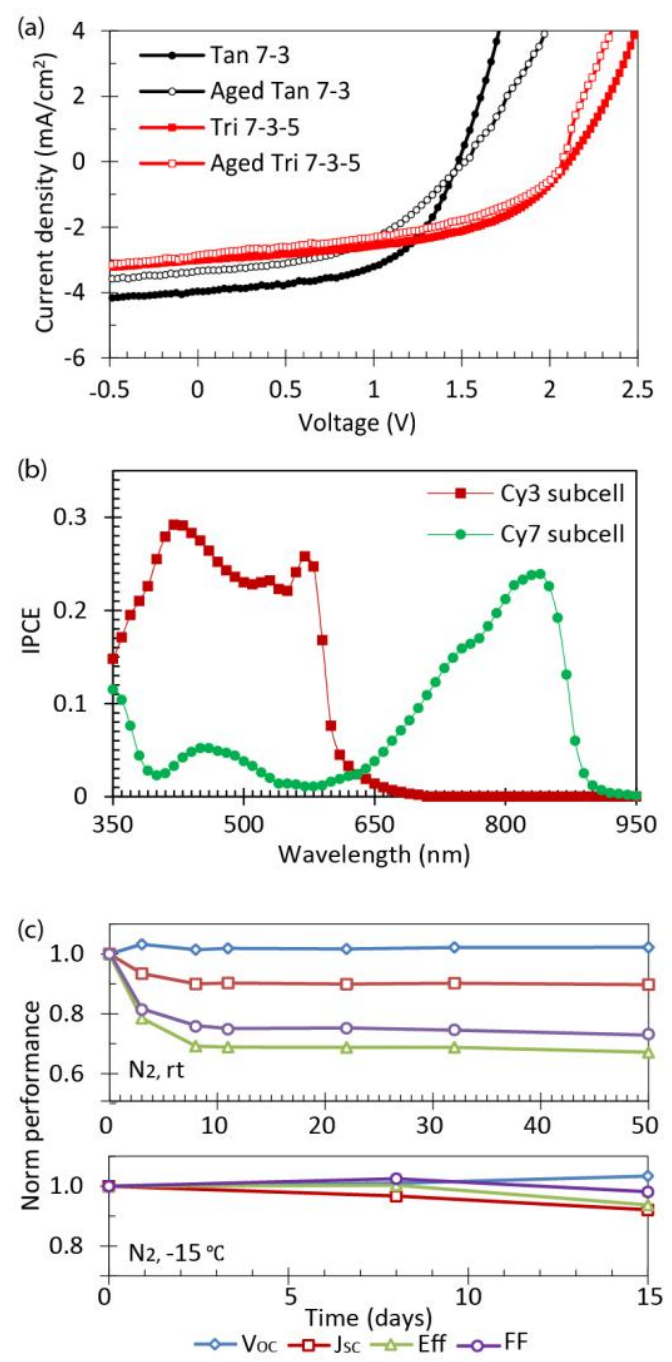

Fig. 6 a) Current-voltage characteristics of a tandem device Tan 7-3 and triple junction device Tri 7-3-5 freshly prepared (full symbols) and after 10 days of aging in the dark under nitrogen (empty symbols). b) IPCE spectrum of tandem device Tan 7-3 after 10 days of aging in the dark, (c) degradation trend of the performance of tandem device Tan 7-3 at room temperature and at $-15^{\circ} \mathrm{C}$. 
To avoid effects of aging, stabilized tandem devices were used for the IPCE measurements as described in the experimental section. The maximum quantum efficiency is rather low and reflects not only the aging of the devices, but also the fact that bilayer heterojunctions are used in this work. IPCE measurements of the individual sub-cells in the tandem stack show almost identical spectra as compared with single junction solar cells, except for the lower quantum yield in the region where $\mathrm{C}_{60}$ absorbs. This comes from the smaller $\mathrm{C}_{60}$ thickness used in the Cy7-T front cell as compared to optimized single layer junctions. In accordance to numerical simulation, current matching is obtained by decreasing the $\mathrm{C}_{60}$ layer thickness of the Cy7-T based front cell with respect to the $\mathrm{C}_{60}$ layer thickness used in the back cell. When convoluting the IPCE in Fig. 6b) with the AM1.5G solar irradiation spectrum, we obtain a short circuit current density $J_{S C}$ of $3.50 \mathrm{~mA} / \mathrm{cm}^{2}$ and $3.12 \mathrm{~mA} / \mathrm{cm}^{2}$ for Cy3-P and Cy7-T based sub-cells, respectively. The currents correspond to the $J_{S C}$ of stabilized devices measured under white light irradiation (Fig. 6a).

The IPCE spectra also reveal the fact that only very little photocurrent is produced between $600 \mathrm{~nm}$ and $700 \mathrm{~nm}$ which led us to the investigation of triple junction devices using Cy5-P with an absorption maximum in precisely above spectral region. As we have elucidated experimentally and by modelling, addition of the supplementary cyanine junction absorbing in this range does not increase the power conversion efficiency with respect to the tandem device (Fig. 3). To investigate this effect experimentally, we attempted to measure the IPCE of triple junction solar cells. Unfortunately, this was not possible with our setup, mainly because the Cy5-P sub-cell could not be saturated selectively. Therefore the IPCE spectra of the front Cy7-T and middle Cy3-P cell always showed a contribution of the Cy5-P cell (supplementary data Fig. S9). Furthermore, by convoluting the IPCE spectra of the individual cells in the stack with the AM1-5G spectrum, the photocurrent $J_{S C}=1.58 \mathrm{~mA} / \mathrm{cm}^{2}$ of the Cy3-P based middle cell of the triple junction solar cell is about $35 \%$ lower than in the bottom and top cell, 
which contradicts the much higher current density of $J_{S C}=2.8 \mathrm{~mA} / \mathrm{cm}^{2}$ observed under white light irradiation of the stabilized triple junction cell Tri 7-3-5.

\section{Conclusion}

Soluble trimethine, pentamethine and heptamethine cyanine dyes with bandgaps of $1.2 \mathrm{eV}$, $1.4 \mathrm{eV}$ and $1.8 \mathrm{eV}$, respectively, were used to construct tandem and triple junction devices. Due to the difficulty to produce bulk-heterojunctions with cyanine dyes, bilayer heterojunction devices so far have reached the highest efficiencies culminating to about $3.7 \%$ for trimethine cyanine based cells. This result is remarkable, if one considers that cyanine dye semiconductors with low charge carrier mobility were employed in this work. Optical simulation of the devices using experimentally determined thicknesses and optical constants revealed losses in the extracted current of $40-50 \%$ if an internal quantum efficiency of 1 is assumed. The modelling studies showed also that tandem and triple junction architectures constructed by stacking cyanine bilayer solar cells with different bandgaps and optimizing the $\mathrm{C}_{60}$ electron acceptor thicknesses of the sub-cells could increase efficiency by $50 \%$ with respect to the best single junction solar cells. At full AM1.5G simulated sunlight irradiation an appreciable increase of $34 \%$ was observed which is believed to be limited by the series resistance induced by the recombination layers. At low light intensity, the power conversion efficiency increase over the best single junction device exceeds $50 \%$ and demonstrates the potential of multijunction devices made from bilayer heterojunction sub-cells. Future work has now to address stability and efficiency of the recombination layers.

\section{Appendix A. Supplementary data}

Supplementary data associated with this article can be found, in the online version, at http://dx.doi.org/ 


\section{Acknowledgements}

The authors would like to thank Dr. Thomas Geiger for interference microscopy studies of

$\mathrm{MoO}_{3}$ thin films. We gratefully acknowledge funding from the Swiss Federal Laboratories for

Materials Science and Technology (Empa), the China Scholarship Council and from the Swiss

National Science Foundation (SNF) under grant number 200021_144120/1.

\section{References}

[1] T.H. James, The theory of the photographic process, 4th ed., Macmillan, New York1977.

[2] P.B. Sargent, Double-Label Immunofluorescence with the Laser-Scanning Confocal Microscope Using Cyanine Dyes, Neuroimage, 1 (1994) 288-295.

[3] H. Mustroph, M. Stollenwerk, V. Bressau, Current developments in optical data storage with organic dyes, Angewandte Chemie-International Edition, 45 (2006) 2016-2035.

[4] A. Mishra, R.K. Behera, P.K. Behera, B.K. Mishra, G.B. Behera, Cyanines during the 1990s: A review, Chem. Rev., 100 (2000) 1973-2011.

[5] R.R. Gupta, Heterocyclic Polymethine Dyes: Synthesis, Properties and Applications, Springer-Verlag, Berlin, 2008.

[6] H. Meier, Organic Dyes as Photoelectric Semiconductors, Angewandte ChemieInternational Edition, 4 (1965) 619-635.

[7] F.S. Meng, K.C. Chen, H. Tian, L. Zuppiroli, F. Nuesch, Cyanine dye acting both as donor and acceptor in heterojunction photovoltaic devices, Applied Physics Letters, 82 (2003) 37883790.

[8] B. Fan, F.A. de Castro, J. Heier, R. Hany, F. Nuesch, High performing doped cyanine bilayer solar cell, Organic Electronics, 11 (2010) 583-588.

[9] E. Berner, T. Jaeger, T. Lanz, F. Nueesch, J.-N. Tisserant, G. Wicht, H. Zhang, R. Hany, Influence of crystalline titanium oxide layer smoothness on the performance of inverted organic bilayer solar cells, Applied Physics Letters, 102 (2013) 183903.

[10] Y. Liu, C.-C. Chen, Z. Hong, J. Gao, Y. Yang, H. Zhou, L. Dou, G. Li, Y. Yang, Solution-processed small-molecule solar cells: breaking the $10 \%$ power conversion efficiency, Scientific Reports, 3 (2013) 3356.

[11] V. Gupta, A.K.K. Kyaw, D.H. Wang, S. Chand, G.C. Bazan, A.J. Heeger, Barium: An Efficient Cathode Layer for Bulk-Heterojunction Solar Cells, Scientific Reports, 3 (2013) 1965.

[12] B. Kan, Q. Zhang, M. Li, X. Wan, W. Ni, G. Long, Y. Wang, X. Yang, H. Feng, Y. Chen, Solution-Processed Organic Solar Cells Based on Dialkylthiol-Substituted Benzodithiophene Unit with Efficiency near 10\%, J. Am. Chem. Soc., 136 (2014) 1552915532 .

[13] Y. Liu, J. Zhao, Z. Li, C. Mu, W. Ma, H. Hu, K. Jiang, H. Lin, H. Ade, H. Yan, Aggregation and morphology control enables multiple cases of high-efficiency polymer solar 
cells, Nat Commun, 5 (2014) 5293.

[14] L. Lu, T. Xu, W. Chen, E.S. Landry, L. Yui, Ternary blend polymer solar cells with enhanced power conversion efficiency, Nature Photonics, 8 (2014) 716-722.

[15] X. Guo, N. Zhou, S.J. Lou, J. Smith, D.B. Tice, J.W. Hennek, R. Ponce Ortiz, J.T. Lopez Navarrete, S. Li, J. Strzalka, L.X. Chen, R.P.H. Chang, A. Facchetti, T.J. Marks, Polymer solar cells with enhanced fill factors, Nature Photonics, 7 (2013) 825-833.

[16] Z. He, C. Zhong, S. Su, M. Xu, H. Wu, Y. Cao, Enhanced power-conversion efficiency in polymer solar cells using an inverted device structure, Nature Photonics, 6 (2012) 591-595.

[17] L. Lu, T. Xu, W. Chen, J.M. Lee, Z. Luo, I.H. Jung, H.I. Park, S.O. Kim, L. Yu, The Role of N-Doped Multiwall Carbon Nanotubes in Achieving Highly Efficient Polymer Bulk Heterojunction Solar Cells, Nano Letters, 13 (2013) 2365-2369.

[18] S. Woo, W.H. Kim, H. Kim, Y. Yi, H.-K. Lyu, Y. Kim, 8.9\% Single-Stack Inverted Polymer Solar Cells with Electron-Rich Polymer Nanolayer-Modified Inorganic ElectronCollecting Buffer Layers, Advanced Energy Materials, 4 (2014) 1301692.

[19] S. Jenatsch, R. Hany, A.C. Veron, M. Neukom, S. Zufle, A. Borgschulte, B. Ruhstaller, F. Nusch, Influence of Molybdenum Oxide Interface Solvent Sensitivity on Charge Trapping in Bilayer Cyanine Solar Cells, Journal of Physical Chemistry C, 118 (2014) 17036-17045.

[20] I. Etxebarria, A. Furlan, J. Ajuria, F.W. Fecher, M. Voigt, C.J. Brabec, M.M. Wienk, L. Slooff, S. Veenstra, J. Gilot, R. Pacios, Series vs parallel connected organic tandem solar cells: Cell performance and impact on the design and operation of functional modules, Solar Energy Materials and Solar Cells, 130 (2014) 495-504.

[21] K. Kawano, N. Ito, T. Nishimori, J. Sakai, Open circuit voltage of stacked bulk heterojunction organic solar cells, Applied Physics Letters, 88 (2006) 073514.

[22] V. Shrotriya, E.H.E. Wu, G. Li, Y. Yao, Y. Yang, Efficient light harvesting in multipledevice stacked structure for polymer solar cells, Applied Physics Letters, 88 (2006) 064104.

[23] J.G. Xue, S. Uchida, B.P. Rand, S.R. Forrest, Asymmetric tandem organic photovoltaic cells with hybrid planar-mixed molecular heterojunctions, Applied Physics Letters, 85 (2004) 5757-5759.

[24] G. Dennler, M.C. Scharber, T. Ameri, P. Denk, K. Forberich, C. Waldauf, C.J. Brabec, Design rules for donors in bulk-heterojunction tandem solar cells-towards $15 \%$ energyconversion efficiency, Advanced Materials, 20 (2008) 579-583.

[25] J. Mescher, S.W. Kettlitz, N. Christ, M.F.G. Klein, A. Puetz, A. Mertens, A. Colsmann, U. Lemmer, Design rules for semi-transparent organic tandem solar cells for window integration, Organic Electronics, 15 (2014) 1476-1480.

[26] B. Minnaert, P. Veelaert, Guidelines for the Bandgap Combinations and Absorption Windows for Organic Tandem and Triple-Junction Solar Cells, Materials, 5 (2012) 19331953.

[27] W.W. Li, A. Furlan, K.H. Hendriks, M.M. Wienk, R.A.J. Janssen, Efficient Tandem and Triple-Junction Polymer Solar Cells, J. Am. Chem. Soc., 135 (2013) 5529-5532.

[28] J.Y. Kim, K. Lee, N.E. Coates, D. Moses, T.Q. Nguyen, M. Dante, A.J. Heeger, Efficient tandem polymer solar cells fabricated by all-solution processing, Science, 317 (2007) 222225.

[29] L.T. Dou, J.B. You, J. Yang, C.C. Chen, Y.J. He, S. Murase, T. Moriarty, K. Emery, G. Li, Y. Yang, Tandem polymer solar cells featuring a spectrally matched low-bandgap 
polymer, Nature Photonics, 6 (2012) 180-185.

[30] D. Cheyns, B.P. Rand, P. Heremans, Organic tandem solar cells with complementary absorbing layers and a high open-circuit voltage, Applied Physics Letters, 97 (2010) 033301.

[31] J.B. You, L.T. Dou, K. Yoshimura, T. Kato, K. Ohya, T. Moriarty, K. Emery, C.C. Chen, J. Gao, G. Li, Y. Yang, A polymer tandem solar cell with $10.6 \%$ power conversion efficiency, Nat Commun, 4 (2013) 1446.

[32] C.C. Chen, W.H. Chang, K. Yoshimura, K. Ohya, J.B. You, J. Gao, Z.R. Hong, Y. Yang, An Efficient Triple-Junction Polymer Solar Cell Having a Power Conversion Efficiency Exceeding 11\%, Advanced Materials, 26 (2014) 5670-5677.

[33] R. Po, A. Bernardi, A. Calabrese, C. Carbonera, G. Corso, A. Pellegrino, From lab to fab: how must the polymer solar cell materials design change? - an industrial perspective, Energy \& Environmental Science, 7 (2014) 925-943.

[34] G. Wicht, S. Buecheler, M. Dietrich, T. Jaeger, F. Nueesch, T. Offermans, J.-N. Tisserant, L. Wang, H. Zhang, R. Hany, Stability of bilayer trimethine cyanine dye/fullerene organic solar cells, Solar Energy Materials and Solar Cells, 117 (2013) 585-591.

[35] A.C. Veron, H. Zhang, A. Linden, F. Nueesch, J. Heier, R. Hany, T. Geiger, NIRAbsorbing Heptamethine Dyes with Tailor-Made Counterions for Application in Light to Energy Conversion, Organic Letters, 16 (2014) 1044-1047.

[36] H. Benmansour, F. A. Castro, M. Nagel, J. Heier, R. Hany, F. Nüesch, Chimia, 61 (2007) 787-791.

[37] M. Lenes and H. J. Bolink, ACS Appl. Mater. Interfaces, 2 (2010), 3664-3668.

[38] W. Eerenstein, L.H. Slooff, S.C. Veenstra, J.M. Kroon, Optical modeling as optimization tool for single and double junction polymer solar cells, Thin Solid Films, 516 (2008) 7188 7192.

[39] B. Fan, High Performance Cyanine Solar Cells, Chemistry and Chemical Engineering, EPFL, Lausanne, Switzerland, 2010, pp. 152.

[40] T. Ameri, N. Li, C.J. Brabec, Highly efficient organic tandem solar cells: a follow up review, Energy \& Environmental Science, 6 (2013) 2390-2413.

[41] G. Dennler, K. Forberich, T. Ameri, C. Waldauf, P. Denk, C.J. Brabec, K. Hingerl, A.J. Heeger, Design of efficient organic tandem cells: On the interplay between molecular absorption and layer sequence, Journal of Applied Physics, 102 (2007) 123109.

[42] R. Timmreck, S. Olthof, K. Leo, M.K. Riede, Highly doped layers as efficient electronhole recombination contacts for tandem organic solar cells, Journal of Applied Physics, 108 (2010) 033108.

[43] Y. Yongbo, H. Jinsong, L. Gang, Intermediate layers in tandem organic solar cells, Green, 1 (2011) 65-80.

[44] Z. Wang, C. Zhang, R. Gao, D. Chen, S. Tang, J. Zhang, D. Wang, X. Lu, Y. Hao, Improvement of transparent silver thin film anodes for organic solar cells with a decreased percolation threshold of silver, Solar Energy Materials and Solar Cells, 127 (2014) 193-200.

[45] J. Gilot, M.M. Wienk, R.A.J. Janssen, Optimizing Polymer Tandem Solar Cells, Advanced Materials, 22 (2010) E67-E71.

[46] X.W. Sun, D.W. Zhao, L. Ke, A.K.K. Kyaw, G.Q. Lo, D.L. Kwong, Inverted tandem organic solar cells with a MoO3/Ag/Al/Ca intermediate layer, Applied Physics Letters, 97 (2010) 053303. 
[47] L. Jian, B. Qin-Ye, W. Huai-Xin, X. Zai-Quan, Y. Jin-Peng, L. Yan-Qing, L. ShuitTong, T. Jian-Xin, Role of transition metal oxides in the charge recombination layer used in tandem organic photovoltaic cells, Journal of materials chemistry, 22 (2012) 6285-6290.

[48] S. Olthof, R. Timmreck, M. Riede, K. Leo, Photoelectron spectroscopy investigations of recombination contacts for tandem organic solar cells, Applied Physics Letters, 100 (2012) 113302.

[49] N. Li, T. Stubhan, J. Krantz, F. Machui, M. Turbiez, T. Ameri, C.J. Brabec, A universal method to form the equivalent ohmic contact for efficient solution-processed organic tandem solar cells, Journal of Materials Chemistry A, 2 (2014) 14896-14902.

[50] J.Y. Lee, T. Lee, H.J. Park, L.J. Guo, Improved solar cell performance by adding ultrathin Alq(3) at the cathode interface, Organic Electronics, 15 (2014) 2710-2714.

[51] Q.L. Song, F.Y. Li, H. Yang, H.R. Wu, X.Z. Wang, W. Zhou, J.M. Zhao, X.M. Ding, C.H. Huang, X.Y. Hou, Small-molecule organic solar cells with improved stability, Chemical Physics Letters, 416 (2005) 42-46.

[52] T. Matsushima, C. Adachi, Temperature-independent electron tunneling injection in tris (8-hydroxyquinoline) aluminum thin film from high-work-function gold electrode, Thin Solid Films, 516 (2008) 5069-5074.

[53] J.A. Macko, R.R. Lunt, T.P. Osedach, P.R. Brown, M.C. Barr, K.K. Gleason, V. Bulovic, Multijunction organic photovoltaics with a broad spectral response, Physical Chemistry Chemical Physics, 14 (2012) 14548-14553.

[54] S.Y. Quek, M.M. Biener, J. Biener, C.M. Friend, E. Kaxiras, Tuning electronic properties of novel metal oxide nanocrystals using interface interactions: $\mathrm{MoO} 3$ monolayers on $\mathrm{Au}(111)$, Surface Science, 577 (2005) L71-L77.

[55] K. Yunbog, D. Jeon, Effect of deposition temperature on the morphology and contact resistance of $\mathrm{Au}$ on pentacene, Journal of Applied Physics, 108 (2010) 016101.

[56] E. Ito, M. Hara, Characterization of organic/metal interfaces using angle-resolved X-ray photoelectron spectroscopy, Japanese Journal of Applied Physics, 47 (2008) 1393-1396.

[57] H. Iddir, S. Ogut, N.D. Browning, M.M. Disko, Adsorption and diffusion of Pt and Au on the stoichiometric and reduced TiO2 rutile (110) surfaces, Physical Review B, 72 (2005) 081407.

[58] A. Bogicevic, S. Ovesson, P. Hyldgaard, B.I. Lundqvist, H. Brune, D.R. Jennison, Nature, strength, and consequences of indirect adsorbate interactions on metals, Physical review letters, 85 (2000) 1910-1913.

[59] D.E. Starr, S.K. Shaikhutdinov, H.J. Freund, Gold supported on oxide surfaces: Environmental effects as studied by STM, Topics in Catalysis, 36 (2005) 33-41. 